\title{
Cyanoacrylate for the Treatment of Small Saphenous Vein Venous Incompetence
}

\author{
Muzaffar A. Anwar $^{1}$, Tristan R. Lane ${ }^{2}$, Ian J. Franklin ${ }^{1}$, Alun H. Davies ${ }^{2}$ \\ 1. Academic Section of Vascular Surgery, Imperial College London 2. Academic Section of Vascular \\ Surgery, Imperial College School of Medicine
}

$\square$ Corresponding author: Tristan R. Lane, tristan.lane@imperial.ac.uk Disclosures can be found in Additional Information at the end of the article

\section{Abstract}

Purpose: Cyanoacrylate (glue) has been successfully used to stop bleeding in gastric varices and cerebral aneurysms. Recently, it has been used successfully in the endovenous closure of incompetent great saphenous veins. We present the first case of successfully treating the small saphenous vein (SSV) with cyanoacrylate.

Case Report: A 67-year-old woman with a history of right leg swelling, discolouration, and pain was treated with VenaSeal ${ }^{\circledR}$ Sapheon Closure for her SSV reflux. No tumescence anaesthesia was used. The procedure was completed with immediate technical success. There were no procedure-related complications. Follow-up at six weeks and four months showed improvement in symptoms and complete occlusion of SSV with no evidence of DVT.

Conclusions: Treatment of SSV with VenaSeal ${ }^{\circledR}$ Sapheon Closure system is feasible.

Received 09/03/2014 Review began 09/03/2014 Review ended 10/21/2014 Published 10/23/2014

C) Copyright 2014

Anwar et al. This is an open access article distributed under the terms of the Creative Commons Attribution License CC-BY 3.0., which permits unrestricted use, distribution, and reproduction in any medium, provided the original author and source are credited.
Categories: Cardiac/Thoracic/Vascular Surgery, General Surgery

Keywords: varicose veins, cyanoacrylate, endovenous ablation, short saphenous vein, case report

\section{Introduction}

Reflux in superficial veins of lower limbs is reported in $15 \%$ of men and $28 \%$ of women [1]. It is associated with the symptoms of pain, aches, discomfort, and leg swelling. Over the past decade, the management of reflux in veins of lower extremities has moved from open surgical treatment (high tie and stripping) to endovenous treatment. Commonly employed endovenous modalities include laser (EVLA) and radio-frequency ablation (RFA). Both treatments are associated with good technical success rates [2]. However, side effects, including postoperative pain and paraesthesia, are not uncommon. Therefore, efforts have been placed on inventing new strategies, which may have better outcomes.

Cyanoacrylate (glue) is not unknown to medical community, and has been in use for peripheral embolization for some years [3]. Recently, the VenaSeal ${ }^{\circledR}$ Sapheon Closure System (Sapheon, Inc., Santa Rosa, CA USA) has been developed with recent publication of two-year follow-up data of the first in man usage of cyanoacrylate for the ablation of great saphenous veins [4]. No previous treatment of the incompetent small saphenous vein (SSV) has been reported.

The aim of this manuscript is to report the first successful case of SSV occlusion with cyanoacrylate. 


\section{Case Presentation}

A 67-year-old female was referred to our clinic with swelling of the right lower leg around the ankle and leg pain. Her right leg was swollen, and there were multiple threads veins affecting her ankles and lower legs. There was no evidence of skin changes. Her CEAP (Clinical Etiology Anatomy Physiology) clinical stage was three. She had normal palpable pulses in her lower limbs, including the feet. Her past medical history included right total knee replacement performed seven years ago that had been revised twice since then. She had also had a deep vein thrombosis (DVT) of the distal femoral vein of her right leg two years prior to treatment, treated with anticoagulation therapy.

Signed informed patient consent was obtained prior to her procedures.

Duplex scan of her lower legs showed an incompetent right saphenofemoral junction, great saphenous vein, saphenopopliteal junction, and small saphenous vein. The superficial femoral vein and a short segment of popliteal vein were incompetent. All veins were patent without any evidence of residual thrombus from the previous DVT. It was decided to treat the SSV initially in order to incrementally improve her symptoms of leg pain and swelling.

\section{Equipment used}

A 7 French (F) access kit was used to access the vein. The VenaSeal ${ }^{\circledR}$ Sapheon Closure System includes a 5 F-delivery catheter, $3 \mathrm{ml}$ syringe, a dispenser tip, custom designed dispenser gun, and a proprietary formulation of cyanoacrylate.

\section{Procedure}

The patient was placed in prone position, following preoperative vein marking by a vascular scientist. The small saphenous vein was cannulated in the distal calf using standard endovenous Seldinger technique under local anaesthetic. The vein was then ablated using standard Sapheon technique. Briefly, the catheter tip was positioned $5 \mathrm{~cm}$ distal to the saphenopopliteal junction (SPJ), and the delivery gun attached. Two treatments were applied to the proximal treatment site $(5 \mathrm{~cm}$ from SPJ), with $1 \mathrm{~cm}$ between applications. Proximal manual compression using the ultrasound probe was applied at the SPJ during the application and for three minutes after. Repeat applications were then completed at $3 \mathrm{~cm}$ intervals, each followed by 30 seconds of mild proximal compression. A total of six applications, treating $15 \mathrm{~cm}$ of vein, were completed. The puncture site was then closed with a steri-strip dressing (3M, St. Paul, MN) and a cannulation site plaster (Mepore; Mölnlycke Health Care, Gothenburg, Sweden). Total treatment time was 10 minutes, including cannulation.

Although stockings are not required for this technique, this patient had deep venous incompetence and consequently wore European Class 2 compression hosiery postoperatively. There were no postoperative complications. The patient was seen in clinic at six weeks and four months postoperatively. The patient reported significant improvement in her pain and swelling, and requested no further treatment; however, she continued with compression hosiery. Duplex closure scan at follow-up showed complete occlusion of short saphenous vein with no evidence of deep vein thrombosis.

\section{Discussion}

This is the first reported ablation of short saphenous vein using the VenaSeal ${ }^{\circledR}$ Sapheon System. Endovenous techniques can now be split into thermal techniques, such as radiofrequency, laser, and steam ablation, and non-thermal techniques, such as mechanochemical (Clarivein device) and chemical (Sapheon device). Thermal techniques are 
based on the principle of using heat energy to denature the vein wall. There is a risk of heat dissipation into the surrounding tissue and the skin, which can cause nerve damage and skin burns. Therefore, tumescent anaesthesia is needed for protection, working as a heat sink, as well as to compress the vein to the catheter, reducing the energy required for satisfactory ablation, again protecting against heat damage. The occurrence of such complications with adequate tumescent anaesthesia is very rare, but the use of tumescence is an additional procedure requiring multiple needle injections, which can be painful. Cyanoacrylate polymerizes when in contact with blood cells and endothelium. In animal models, the cyanoacrylate treated vein showed a granulomatous type inflammatory response with presence of giant cells, segmental wall thickening, and fibrosis [5]. This suggests extremely low risk of damage to the surrounding structures and skin, thus removing the requirement for any additional procedures, such as tumescent anaesthesia. Reports of complications following administration of this proprietary blend of cyanoacrylate are rare and lacking in the literature; however, other formulations, such as tissue adhesives, have led to granuloma formation and rarely pulmonary embolism after embolisation of gastric varices [6-7].

This single case report demonstrates a novel technique but needs further study with case series and awaits the publication of randomised trials. The technical limitations of this technique are yet to be fully established, with no maximum diameter identified.

\section{Conclusions}

We propose the use of cyanoacrylate (VenaSeal ${ }^{\circledR}$ Sapheon Closure System) as a viable treatment option for SSV reflux. Future large studies comparing the use of EVLT, RFA, and Sapheon glue closure system for SSV reflux are required to identify the most effective and safe treatment modality.

\section{Additional Information \\ Disclosures}

Human subjects: Consent was obtained by all participants in this study. Conflicts of interest: In compliance with the ICMJE uniform disclosure form, all authors declare the following: Payment/services info: All authors have declared that no financial support was received from any organization for the submitted work. Financial relationships: All authors have declared that they have no financial relationships at present or within the previous three years with any organizations that might have an interest in the submitted work. Other relationships: All authors have declared that there are no other relationships or activities that could appear to have influenced the submitted work.

\section{Acknowledgements}

We thank Sapheon, Inc. for providing the Venaseal Sapheon Closure Device for evaluation. The research was supported by the National Institute for Health Research (NIHR) Biomedical Research Centre based at Imperial College Healthcare NHS Trust and Imperial College, London. The views expressed are those of the authors and not necessarily those of the NHS, NIHR, or the Department of Health.

\section{References}

1. Criqui MH, Jamosmos M, Fronek A, et al.: Chronic venous disease in an ethnically diverse population: The San Diego Population Study. Am J Epidemiol. 2003, 158:448-56.

2. Rasmussen LH, Lawaetz M, Bjoern L, et al.: Randomized clinical trial comparing endovenous laser ablation, radiofrequency ablation, foam sclerotherapy and surgical stripping for great saphenous varicose veins. Br J Surg. 2011, 98:1079-87. 10.1002/bjs.7555 


\section{Cureus}

3. Pollak JS, White RI Jr: The use of cyanoacrylate adhesives in peripheral embolization . J Vasc Interv Radiol. 2001, 12:907-13.

4. Almeida JI, Javier JJ, Mackay EG, Bautista C, Cher DJ, Proebstle TM: Two-year follow-up of first human use of cyanoacrylate adhesive for treatment of saphenous vein incompetence. Phlebology . 2014, Apr 30. [Epub ahead of print].

5. Almeida JI, Min RJ, Raabe R, McLean DJ, Madsen M: Cyanoacrylate adhesive for the closure of truncal veins: 60-day swine model results. Vasc Endovascular Surg. 2011, 45:631-5.

10.1177/1538574411413938

6. Chew JRY, Balan A, Griffiths W, Herre J: Delayed onset pulmonary glue emboli in a ventilated patient: a rare complication following endoscopic cyanoacrylate injection for gastric variceal haemorrhage. BMJ Case Rep. 2014, pii: bcr2014206461. 10.1136/bcr-2014-206461

7. Jagannathan N, Hallman M: Complications associated with 2-octyl cyanoacrylate (Dermabond): Considerations for the anesthesiologist. J Clin Anesth. 2010, 22:71-2. 10.1016/j.jclinane.2009.03.012 